\title{
Commentary
}

\section{John Maynard Smith 6 January 1920-19 April 2004}

I first met John Maynard Smith in 1979 when he came to India to participate in the Mahabaleshwar Seminar on Modern Biology (figure 1). The theme of the Seminar that year was 'Evolution of Social Behaviour'. It was an extraordinarily lively meeting, held just when the sociobiology debates were hotting up. I still remember his talk vividly. He spoke on Group Selection and the fallacy of WynneEdwards's approach, which depended on the existence of adaptations that were advantageous to the group but disadvantageous to the individual. Mahabaleshwar is a picturesque hill resort and no one who goes there can forget the loud, periodic, synchronous calls of hundreds of cicadas. Right in the middle of Maynard Smith's lecture, just when he was describing Wynne-Edwards's theory, there erupted a burst of cicada singing. In an impressively rapid reaction, Maynard Smith said something along the following lines: "If Wynne-Edwards were here he would surely have argued that the cicadas are singing in unison in order to assess their population density. Then they would adjust their rate of reproduction so that the habitat would not be over-exploited and the species would not run the risk of going extinct". David Lack and George C Williams had done much in the 1960s to discipline biologists against making such naive group selectionist arguments. But it was the publication of two brief letters to Nature, one by Maynard Smith and the other by Christopher Perrins, that really began to clarify the issues of levels of selection - an issue that has been central to evolutionary biology ever since. It is due to this clarification that we recognize today the power of individual selection, recognize the need for kin

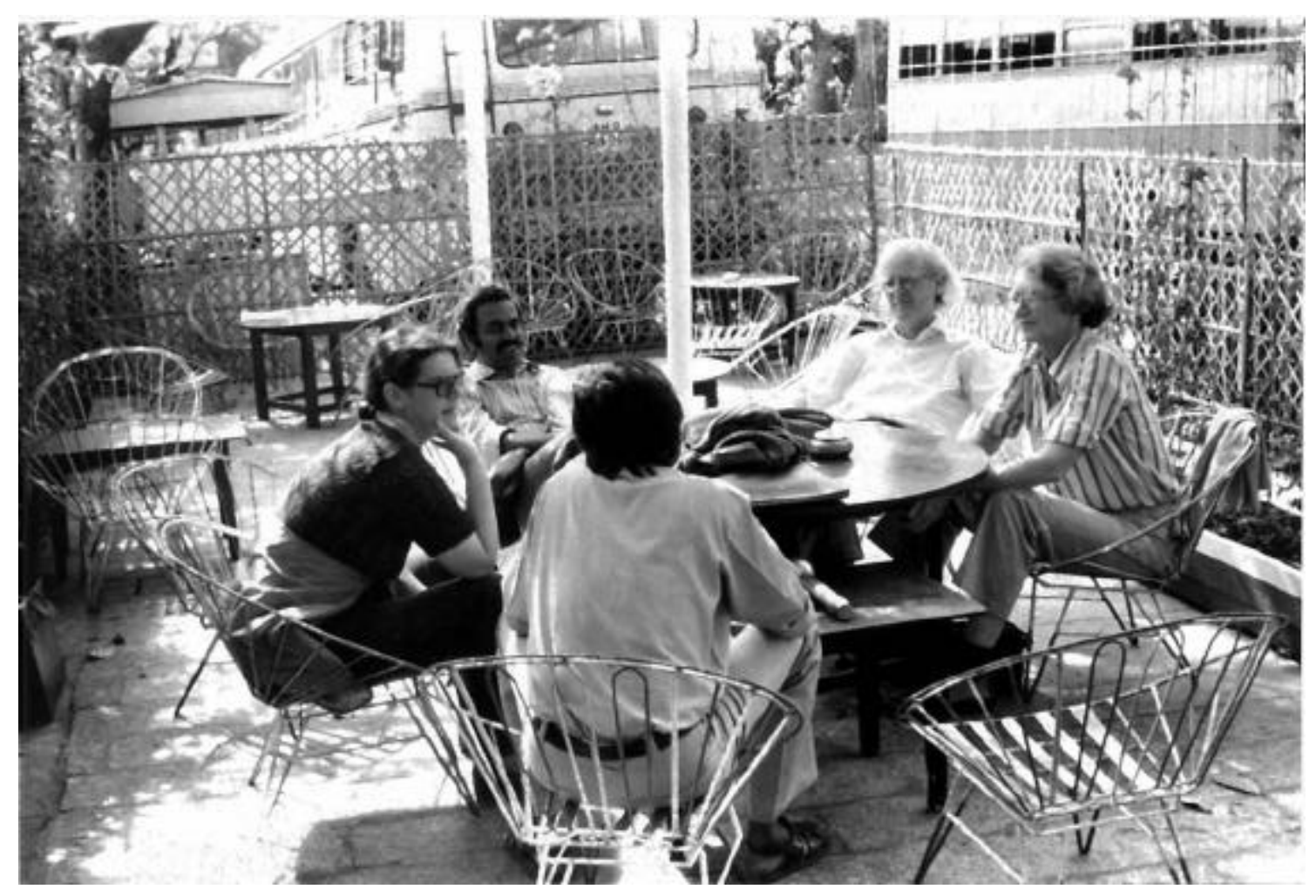

Figure 1. John and Sheila Maynard Smith with a group of participants including M K Chandrashekaran (to his right). Taken during the Mahabaleshwar Seminar on Modern Biology, 1979 (courtsey: K Usman). 
selection to explain bona fide examples of altruism and are prepared to consider cases of genuine group selection.

Trained as an engineer, rejected by the army on account of his poor eyesight, Maynard Smith worked on mechanical stress in aeroplanes during the Second World War. Later he studied Drosophila genetics under JBS Haldane at University College, London. Over the next fifty years he went on to tackle nearly every fundamental unsolved problem in evolutionary biology. He did so by using persuasive arguments, mathematical models and lucidly written books The Theory of Evolution (1958), Models in Ecology (1974), The Evolution of Sex (1978), Evolution and The Theory of Games (1982), The Problems of Biology (1986), Evolutionary Genetics (1989), The Major Transitions of Evolution (1997), The Origins of Life (1999), Animal Signals (2003) -the titles of John Maynard Smith's books tell his life's tale. He spent most of his career in the school of Biological Sciences, University of Sussex, which he helped found.

Perhaps Maynard Smith is best known for applying game theory (along with George Price) to the study of animal behaviour and evolution. Puzzled by why animals in conflict do not seriously injure or kill each other more often than they do, he turned to game theory for a possible explanation. Game theory was originally developed by John von Neumann to analyse the strategies that succeed in games such as chess and poker. Maynard Smith realized that animals in conflict with each other, over food, territory, mates or even over how many sons and daughters to produce, are in a similar situation. The basic point he made was that the costs and benefits of any individual's behaviour could be assessed only in the context of what other individuals did. He developed the concept of an Evolutionarily Stable Strategy (ESS) to show why a pure population of 'Hawks' (animals that always escalate a fight) is susceptible to invasion by 'Doves' (animals that quickly retreat if their opponent escalates) and similarly, a pure population of Doves is susceptible to invasion by Hawks. He concluded and that the only stable situation possible was a mixture of Hawk and Dove strategies.

Thanks to Maynard Smith, the evolution of sex, another major paradox in evolutionary biology, became at least less paradoxical. His popularization of the 'two-fold cost' of sex led to a widespread appreciation that the evolution of sex was inherently puzzling. In his characteristically simple style, Maynard Smith argued that a sexually reproducing female will invest half her resources in males, while a parthenogenetic female can produce all daughters, and therefore twice as many daughters. Simple algebra led him infer that because of this, there is an approximately two-fold reproductive advantage to the parthenogenetic female (when it is rare), or a two-fold cost to the sexually reproducing female. Thus any advantage that sexual reproduction possesses needs to be large enough to offset the two-fold cost.

Maynard Smith made it his business to tackle the most difficult problems in evolutionary biology. While our understanding of microevolution is often sufficient to explain gradual, 'linear' changes, seemingly abrupt, large-scale changes have always remained problematic. This problem was addressed comprehensively in The Major Transitions in Evolution by Eörs Száthmary and Maynard Smith, in which they discussed such major transitions as the origin of life, eukaryotic cells, sex, multicellularity, cooperation and animal societies. Száthmary and Maynard Smith followed up with a more widely accessible 'bird watcher's version' of the book called The Origins of Life (1999).

Maynard Smith's last book, Animal Signals, was co-authored with David Harper (2003). It addresses another issue that interested him throughout his life. There is an obvious problem in understanding the evolution of animal signals in particular and of animal communication in general: why is cheating not more common, why don't animals bluff when it is of obvious advantage for them to do so? In the 1970s Amotz Zahavi developed the Handicap Principle, and in doing so, offered an explanation for why biological signals are 'honest'. As an illustration of Zahavi's argument, consider the peacock's tail. Biologists since Darwin have wondered why the peacock has such an elaborate train that it must be a hindrance to it in many ways - for example, while running away from predators. The common response has been to develop models that show how the peacock's train can evolve in spite of being a handicap. Zahavi made the counter-intuitive suggestion that the peacock's long train is selected precisely because it is a handicap. By carrying the burden of the train successfully - that is, by not having succumbed to a predator - the peacock reliably demonstrates to females that he is fit enough to survive despite the handicap. Zahavi derived from this idea a far-reaching general principle: namely, that in order to be reliable, animal signals must impose a cost, a handicap, on the signaler, and thereby be resistant to faking by other individuals that are intrinsically less well-endowed. Many in the scientific 
community, including Maynard Smith, rejected Zahavi's argument. Things changed in 1990. Alan Grafen published two papers that showed, with the aid of mathematical models, that Zahavi's handicap principle could indeed work, both in the evolution of honest signals in general and in the context of sexual selection. Maynard Smith admitted publicly that he was wrong in hastily concluding that Zahavi's idea was in error: "I was cynical about the idea when I first heard it, essentially because it was expressed in words rather than in a mathematical model. This may seem an odd reason, but I remain convinced that formal models are better than verbal ones, because they force the theorist to say precisely what he means. However, in this case my cynicism was unjustified. It has proved possible to formulate mathematical models showing that what Zahavi called the 'handicap principle' can lead to the evolution of honest signals." (The Times Literary Supplement, August 3 2001). Nevertheless, Maynard Smith cautioned that it would be a mistake to interpret all signals in this way. He maintained that there would a number of signals that are inexpensive and reliable, like railway time-tables (a phrase he used to describe such signals). In such cases there would be no conflict of interest, because both sender and receiver would benefit from the reliability of the signal.

Maynard Smith often raised important points and provided new insights in biology without following them up himself. Partly because he constantly produced new and significant work, his earlier work, especially the work he did in the 1950s and 1960s, has remained under-appreciated. Two areas which illustrate this are sexual selection and pattern formation in development. His 'Fertility, Mating Behaviour and Sexual Selection in Drosophila subobscura' (J. Genetics, 54, 261-279, 1956) is a pioneering study of sexual selection that reads like a paper written in the 1990s. Together with K. C. Sondhi, Maynard Smith carried out elegant experiments on the genetics of bristle pattern in Drosophila long before the genetics of pattern was made famous by Nüsslein-Volhard, Wieschaus and others. In Mathematical Ideas in Biology (1968), he highlighted the possible role of diffusion in morphogenesis and re-stated the Turing model in terms of what subsequently came to be called 'short-range activation, long-range inhibition'. Similar insights are to be found in The Problems of Biology (1986).

During the last ten years or so Maynard Smith collaborated with many colleagues and turned his attention to bacterial evolution and the evolution of recombination. The evolution of antibiotic resistance in Mycobacterium tuberculosis, which has no recombination, puzzled him and led him to study the role of mutator genes in adaptive evolution. The signatures of recombination in mitochondrial DNA made him question the use of mitochondrial DNA for dating events in the history of life. Maynard Smith received numerous honours including the fellowship of the Royal Society of London (1977), the Royal Society's Darwin Medal (1986) and Royal Medal (1997), the Balzan Prize (1991), the Linnean Medal of the Linnean Society (1995), the Crafoord Prize (1999) (awarded by the Swedish Academy of Sciences to scientists in fields not eligible for the Nobel prizes) and the Kyoto Prize (2001), Japan's highest award for lifetime achievement in science. Maynard Smith's lifetime work is far too important and well known to require any mention of these honours. However, I think the fields he worked in are still too poorly recognized and will benefit from a list of his awards and honours. At the time he died he was working on research papers, popular articles and books. John Maynard Smith leaves behind his wife Sheila, two sons and a daughter and numerous students, colleagues, friends and admirers to celebrate his life.

\section{References}

Maynard Smith J 1964 Group selection and kin selection; Nature (London) 201 1145-1147

Maynard Smith J and Sondhi K C 1960 The genetics of pattern; Genetics 45 1039-1050

Perrins C 1964 Survival of young swifts in relation to brood-size; Nature (London) 201 1147-1148

RAGHAVENDRA GADAGKAR

Centre for Ecological Sciences,

Indian Institute of Science,

Bangalore, 560 012, India, and

Evolutionary and Organismal Biology Unit,

Jawaharlal Nehru Centre for Advanced

Scientific Research,

Jakkur, Bangalore, 560 064, India

(Email,ragh@ces.iisc.ernet.in) 